\title{
PENDEKATAN-PENDEKATAN MANAJEMEN PERSONALIA
}

\author{
Oleh: Nuraini \\ SDN 311 Takkalala, Palopo
}

\begin{abstract}
Abstrak:
Manajemen personalia telah dilaksanakan sejak dulu oleh nenek moyang kita, hal ini ternyata dengan adanya bangunan seperti Borobudur, Piramid di Mesir dan sebagainya. Meskipun demikian karena situasi dan kondisi berubah serta kebutuhan yang mendesak, maka sejak abad ke-20 manajemen personalia mulai dekembangkan dan diusahakan untuk diterapkan. Untuk dapat mengembangkan manajemen personalia maka kita harus sadar bahwa manusia bukanlah benda mati sebab manusia mempunyai perasaan, mereka dapat gembira dan sakit hati , mereka dapat senan dan susah , mereka bukan hanya memerlukan kebutuhan materi tetapi juga mereka juga sering mengharapkan penghargaan dan pengakuaan Dalam mempelajari MSDM ada 3 (tiga) pendekatan yang dapat dilakukan yaitu: (1) Pendekatan mekanis; $\quad$ (2) Pendekatan paternalis, dan (3) Pendekatan sistim sosial.
\end{abstract}

\section{Kata Kunci: Pendekatan, Manajemen, Personalia}

\section{A. PENGANTAR}

Keberadaan tenaga kerja sebagai salah satu faktor produksi sangat penting artinya bagi organisasi. Dalam perkembangannya, organisasi akan menghadapi permasalahan tenaga kerja yang semakin kompleks, dengan demikian pengelolaan sumber daya manusia harus dilakukan secara profesional oleh departemen tersendiri dalam suatu organisasi, yaitu Human Resource Departemen (Manajemen Sumber Daya Manusia). Manajemen Sumber Daya Manusia atau yang lebih dikenal dengan Manajemen Personalia adalah manajemen yang mengkhususkan diri dalam bidang personalia atau dalam kepegawaiaan.

Manajemen personalia adalah suatu ilmu dan seni untuk melaksanakan antara lain planning, organizing dan kontroling sehingga efektivitas dan efisiensi personalia dapat ditingkat kan semakasimal mungkin. Memang hrus kita ketahui bahwa sukses tidaknya suatu perusahaan /instansi tidak hanya tergantung dari kegiatan dalam bidang personalia , meskipun demikian peranan manajemen personalia cukup besar andilnya terhadap sukses tidaknya. 
Manajemen personalia telah dilaksanakan sejak dulu oleh nenek moyang kita , hal ini ternyata dengan adanya bangunan seperti Borobudur, Piramid di Mesir dan sebagainya. Meskipun demikian karena situasi dan kondisi berubah serta kebutuhan yang mendesak, maka sejak abad ke-20 manajemen personalia mulai dekembangkan dan diusahakan untuk diterapkan.

Untuk dapat mengembangkan manajemen personalia maka kita harus sadar bahwa manusia bukanlah benda mati sebab manusia mempunyai perasaan, mereka dapat gembira dan sakit hati, mereka dapat senan dan susah, mereka bukan hanya memerlukan kebutuhan materi tetapi juga mereka juga sering mengharapkan penghargaan dan pengakuaan .

Oleh karena demikiaan banyak factor yang merupakan asfek dalam kehidupan manusia dalam hubungannya antara satu dengan yang lain, maka untuk mengembangkannya perlu pengetahuaan tentang fsikologi, hubungan tentang manusia agama,adat-istiadat dan sebagainya. Memang harus kita akui bahwa makin kecil suatu perusahaan, maka makin kecillah peranan menajemen personalia. Sebaliknya dengan makin besarnya suatu perusahaan maka makin besarlah peranan manajemen personalia disini. Hal ini dapat kita mengerti, sebab makin besar suatu perusahaan maka kecendrungan makin besarlah jumlah personalianya. Dan ini berarti makin dibutuhkan administrasi yang lebih baik, pengurusan yang lebih baik, kebijakan-kebijakan yang lebih baik dan sebagainya. Ini disebabkan karena makin besarnya jumlah personalia, bukan hanya makin besar jumlah yang harus diurus tetapi kecendrungan makin kompleks persoalan yang harus dihadapi.

\section{B. PENTINGNYA MANAJEMEN SUMBER DAYA MANUSIA ( MSDM )}

Manajemen adalah ilmu dan seni mengatur proses pemanfaatan sumber daya manusia dan sumber-sumber daya lainnya secara efektif dan efisien untuk mencapai suatu tujuan tertentu. Unsur-unsur manajemen yaitu: men, money, methode, materials, machines, dan market ( $6 \mathrm{M}$ ). Unsur men ( manusia ) berkembang menjadi suatu ilmu manajemen sumber daya manusia yang disingkat MSDM yang adalah terjemahan dari man power management. Manajemen yang mengatur unsur manusia disebut manajemen 
personalia ( personnel management ).Persamaan dan perbedaan antara MSDM dan manajemen personalia yaitu:

Persamaan : Keduanya adalah ilmu yang mengatur unsur manusia dalam suatu organisasi, agar mendukung terwujudnya tujuan. Perbedaan :

1. MSDM dikaji secara makro, sedangkan manajemen personalia dikaji secara mikro.

2. MSDM menganggap bahwa karyawan adalah kekayaan (asset) utama organisasi, sedangkan manajemen personalia menganggap bahwa karyawan adalah faktor produksi.

3. MSDM pendekatannya secara modern, sedangkan manajemen personalia pendekatannya secara klasik.

MSDM adalah suatu bidang manajemen yang mempelajari hubungan dan peranan manusia dalam organisasi perusahaan. Jadi fokus yang dipelajari MSDM hanya masalah yang berkaitan dengan tenaga kerja manusia saja. MSDM lebih memfokuskan pembahasannya tentang pengaturan peranan manusia dalam mewujudkan tujuan yang optimal yang meliputi masalah perencanaan (human recources planning), pengorganisasian, pengarahan, pengendalian, pengadaan, pengembangan, kompensasi, pengintegrasian, pemeliharaan, kedisiplinan, dan pemberhentian tenaga kerja.

\section{DEFINISI MSDM}

\section{Drs. Malayu S.P. Hasibuan}

MSDM adalah ilmu dan seni yang mengatur hubungan dan peranan tenaga kerja agar efektif dan efisien membantu terwujudnya tujuan perusahaan, karyawan dan masyarakat. Fungsi-fungssi MSDM terdiri dari perencanaan, pengorganisasian, pengarahan, pengendalian, pengadaan, pengembangan kompensasi, pengintegrasian, pemeliharaan, kedisiplinan dan pemberhentian.

\section{Edwin B. Flippo}

Personnel management is the planning, organizing, directing and controlling of the procurement, development, compensation, integration, maintenance, and separation of human recources to the end that individual, organizational and societal objectives are accomplished. (Manajemen personalia adalah perencanaan, pengorganisasian, pengarahan, dan pengendalian dai pengadaan, pengembangan, kompensasi, 
pengintegrasian, pemeliharaan dan pemberhentian karyawan, dengan maksud terwujudnya tujuan perusahaan, individu, karyawan, dan masyarakat ).

\section{Dale Yoder}

Personnel management is the provision of leadership and directionof people in their working or employmentrelationship. (Manajemen personalia adalah penyedia kepemimpinan dan pengarahan para karyawan dalam pekerjaan atau hubungan kerja mereka).

\section{Andrew F. Sikula}

Personnel administration is the implementation of hman recources( man power ) by and within an enterprise. (Administrasi kepegawaian adalah penempatan orang-orang kedalam suatu perusahaan). Implementasi tenaga kerja manusia adalah pengadaan, pemeliharaan, penempatan, indoktrinasi, latihan dan pendidikan sumber daya manusia (human recources atau man power). Implementasi sumber daya manusia adalah: recruitment, selection, training, education, placement,indoctrination, dan development.

\section{Jonh B. Miner dan Mary Green Miner}

Personnel management may be defined as the process of developing, applying and evaluating policies, procedures, methods, and program relatingto the individual in the organization. (Manajmen personalia didefinisikan sebagai suatu proses pengembangan, menerapkan, dan menilai kebijakan-kebijakan, prosedur-prosedur, metode-metode, dan program-program yang berhubungan dengan individu karyawan dalam organisasi).

\section{Michel J. Jucius}

(Manajemen personalia adalah lapangan manajemen yang bertalian dengan perencanaan, pengorganisasian, dan pengendalian bermacam-macam fungsi pengadaan, pengembangan, pemeliharaan, dan pemanfaaatan tenaga kerja sedemikian rupa sehingga: Tujuan untuk apa perkumpulan didirikan dan dicapai secara efektif, Tujuan semua pegawai dilayani, dan Tujuan masyarakat diperhatikan dan dilayani dengan baik).

\section{KOMPONEN MSDM}

Tenaga kerja manusia pada dasarnya dibedakan atas pengusaha, karyawan dan pemimpin. Posisi karyawan dalam suatu perusahaan dibedakan atas 2 yaitu: a. Karyawan Operasional adalah setiap orang yang secara langsung harus mengerjakan sendiri pekerjaannya sesuai dengan perintah atasan. b. Karyawan Manajerial adalah 
setiap orang yang berhak memerintah bawahannya untuk mengerjakan sebagian pekerjaannya dan dikerjakan sesuai dengan perintah. Mereka mencapai tujuannya melalui kegiatan-kegiatan orang lain. Karyawan manajerial dibedakan menjadi 2, yaitu:

1. Manajer Lini adalah seorang pemimpin yang mempunyai wewenang lini (line uthority), berhak dan bertanggung jawab langsungmerealisasi tujuan perusahaan.

2. Manajer staff adalah pemimpin yang mempunyai wewenang staf (staff authority) yang hanya berhak memberikan saran dan pelayanan untuk memperlancar penyelesaian tugas-tugas manajer lini.

\section{E. PERANAN MSDM}

MSDM mengatur dan menetapkan program kepegawaian yang mencakup masalah-masalah sebagai berikut.

1. Menetapkan jumlah, kualitas, dan penempatan tenaga kerja yang efektif sesuai dengan kebutuhan perusahaan berdasarkan job description (uraian $\mathrm{P}$ ), job specification (spesifikasi P), job requirement (persyaratan $\mathrm{P}$ ), dan job evalution (Evaluasi P).

2. Menetapkan penarikan, seleksi, dan penempatan karyawan berdasarkan asas the right man in the right place and the right man in the right job (Orang yang tepat di tempat yang tepat dan orang yang tepat pada posisi yang tepat)

3. Menetapkan program kesejahteraan, pengembangan, promosi, dan pemberhentian.

4. Menawarkan penawaran dan permintaan sumber daya manusia pada masa yang akan datang.

5. Memperkirakan keadaan perekonomian pada umumnya dan perkembangan perusahaan pada khususnya.

6. Memonitor dengan cermat UU perburuhan dan kebijaksanaan pemberian balas jasa perusahaan-perusahaan sejenis.

7. Memonitor kemajuan teknik dan perkembangan serikat buruh.

8. Melaksanakan pendidikan, latihan, dan penilaian prestasi karyawan.

9. Mengatur mutasi karyawan baik vertikal maupun horizontal.

10. Mengatur pensiun, pemberhentian, dan pesangonnya. 
Seorang karyawan selain mampu, cakap, dan terampil harus mempunyai kemauan dan kesanggupan dan didukung moral kerja dan kedisiplinan karyawan dalam mewujudkan tujuan.

\section{F. PERKEMBANGAN MSDM}

Perkembangan MSDM didorong oleh kemajuan peradaban, pendidikan, ilmu pengetahuan, dan tuntutan daya saing produksi barang dan jasa yang dihasilkan. Para ahli abad ke- 20 mengembangkan MSDM menjadi suatu bidang studi yang khusus mempelajari peranan dan hubungan manusia dalam mencapai tujuan. Perkembangan MSDM didorong oleh masalah-masalah ekonomis, politis, dan sosial. Masalah ekonomis meliputi hal-hal sebagai berikut:

1. Semakin terbatasnya faktor-faktor produksi menuntut agar sumber daya manusia dapat bekerja lebih efektif dan efisien.

2. Semakin disadari bahwa sumber daya manusia paling berperan dalam mewujudkan tujuan perusahaan, karyawan, dan masyarakat.

3. Karyawan akan meningkatkan modal kerjanya jika kepuasan diperolehnya dari pekerjaannya.

4. Terjadinya persaingan yang tajam untuk mendapatkan tenaga kerja yang berkualitas diantara perusahaan.

\section{G. METODE PENDEKATAN MSDM}

Dalam mempelajari MSDM ada 3 (tiga) pendekatan yang dapat dilakukan yaitu:

1. Pendekatan mekanis

2. Pendekatan paternalis, dan

3. Pendekatan sistim sosial.

Kebaikan dan kelemahan dari masing-masing pendekatan di atas yaitu:

1. Pendekatan Mekanis.

Mekanisasi (otomatisasi) adalah mengganti peranan tenaga kerja manusia dengan tenaga mesin untuk melakukan pekerjaan sesuai dengan pertimbangan ekonomis, kemanusiaan, efektifitas, dan kemampuan yang lebih besar dan lebih baik. Lebih menitikberatkan pada spesialisasi, efektifitas, standardisasi, dan memperlakukan karyawan sama dengan mesin. Pembagian pekerjaan semakin mendetail, seorang 
pekerja hanya mengerjakan satu pekerjaan saja. Keuntungannya pekerja semakin trampil dan efektifitas semakin besar. Kelemahannya, pekerjaan membosankan para pekerja, mematikan kreatifitas, dan kebanggaan dalam bekerja semakin berkurang. Terjadi pemindahan pekerjaan dari manusia kepada mesin. Pendekatan mekanis ini akan mengakibatkan timbulnya masalah-masalah :
a) Pengaangguran Teknologis
b) Keamanan Ekonomis
c) Organisasi Buruh
d) Kebanggaan dalam Pekerjaan

2. Pendekatan Paternalis

Pada pendekatan paternalis (paternalistic approach), manajer untuk pengarahan bawahannya bertindak seperti Bapak terhadap anak-anaknya. Para bawahan diperlakukan dengan baik diberikan fasilitas-fasilitas yang baik, bawahan dianggapnya sebagai anakanaknya. Dapat mengakibatkan karyawan menjadi manja, malas sehingga produktifitas kerja menurun.

\section{Pendekatan Sistim Sosial}

Menganggap bahwa perusahaan adalah suatu sistem yang kompleks yang beroperasi dalam suatu lingkungan yang kompleks yang disebut sistem yang diluar. Manajer mengakui dan menyadari bahwa tujuan perusahaan dapat tercapai jika terbina kerjasama yang harmonis antara sesama karyawan, bawahan dengan atasan. Adanya saling ketergantungan, interaksi dan keterkaitan diantara sesama karyawan. Setiap karyawan betapapun rendah kedudukannya dan kecil jasanya tetap mendapat penghargaan yang baik.

Sistem: suatu proses yang terdiri dari berbagai unsur atau komponen yang satu sama lain berkaitan secara struktural dan fungsional, salimg menunjang dan mengisi, sesuai dengan peran dan kedudukan masing-masing namun keseluruhannya secara mutlak didukung oleh setiap komponen, betapapun kecil nilainya. Sistem mengandung masukan (input), proses, keluaran (output), dan merupakan sebuah kesatuan yang bekerja sendiri. Pendekatan sistem sosial ini lebih menekankan pada hubungan harmonis, interaksi yang baik, saling menghargai dan membutuhkan, dan saling mengisi sehingga 
terdapat suatu total sistem yang baik. Komunikasi yang diterapkan adalah komunikasi dua arah (twoway trafic) dan umpan balik (feed back) yang positif.

\section{H. FUNGSI MSDM}

\section{Perencanaan (planning)}

Perencanaan (human recources planning) adalah merencanakan tenaga kerja secara efektif serta efisien agar sesuai dengan kebutuhan perusahaan dalam membantu terwujudnya tujuan. Dilakukan dengan menetapkan program kepegawaian yang meliputi pengendalian, pengadaan, pengembangan, kompensasi, pengintegrasian, pemeliharaan, kedisiplinan, dan pemberhentian karyawan.

\section{Pengorganisasian (organizing)}

Adalah kegiatan untuk mengorganisasi semua karyawan dengan menetapkan pembagian kerja, hubungan kerja, delegasi wewenang, integrasi dan koordinasi dalam bagan organisasi (organization chart). Organisasi hanya alat untuk mencapai tujuan. Dengan organisasi yang baik akan membantu terwujudnya tujuan secara efisien.

\section{Pengarahan (directing).}

Kegiatan mengarahkan semua karyawan agar mau bekerja sama dan bekerja efektif serta efisien untuk mencapai tujuan yang telah ditetapkan bersama. Pengarahan dilakukan oleh pimpinan dengan menugaskan bawahan agar mengerjakan semua tugas dengan baik.

\section{Pengendalian ( controling)}

Adalah kegiatan mengendalikan semua karyawan, agar taat kepada peraturan perusahaan dan bekerja sesuai dengan rencana. Jika terdapat penyimpangan/kesalahan diadakan tindakan perbaikan dan perubahan rencana. Pengendalian karyawan meliputi: kehadiran, kedisiplinan, perilaku, kerjasama, pelaksanaan pekerjaan, dan menjaga situasi lingkungan pekerjaan.

\section{Pengadaan ( procurement)}

Proses penarikan seleksi, penempatan, orientasi, dan induksi untuk mendapatkan karyawan yang sesuai dengan kebutuhan perusahaan. Pengadaan yang baik akan membantu terwujudnya tujuan. 


\section{Pengembangan (development)}

Proses peningkatan ketrampilan teknis, teoretis, konseptual, dan moral karyawan melalui pendidikan dan pelatihan. Pendidikan dan pelatihan yang duberikan harus sesuai dengan kebutuhan pekerjaan masa kini maupun masa depan.

\section{Kompensasi ( compensation)}

Pemberian balas jasa langsung ( direct ) dan tidak langsung ( indirect ), uang atau barang kepada karyawan sebagai imbalan jasa yang diberikankepada perusahaan. Prinsip kompensasi adalah adil dan layak. Adil diartikan sesuai dengan prestasi kerjanya, layak diartikan dapat memenuhi kebutuhan primernya serta berpedoman pada batas upah minimum pemerintah dan berdasarkan internal dan eksternal konsitensi.

\section{Pengontegrasian (integration)}

Kegiatan untuk mempersatukan kepentingan perusahaan dan kebutuhan karyawan, agar tercipta kerjasama yang serasi dan saling menguntungkan. Perusahaan memperoleh laba, karyawan dapat memenuhi kebutuhan dari hasil pekerjaannya. Pengintegrasian merupakan hal yang penting dan sulit dalam MSDM, karena mempersatukan dua kepentingan yang bertolak belakang.

\section{Pemeliharaan (maintenance)}

Kegiatan untuk memelihara atau meningkatkan kondisi fisik, mental dan loyalitas karyawan, agar tetap mau bekerja sama sampai pensiun. Pemeliharaan yang baik dilakukan dengan program kesejahteraan yang berdasarkan kebutuhan sebagian besar karyawan serta berpedoman kepada internal dan eksternal konsistensi.

\section{Kedisiplinan}

Merupakan fungsi MSDM yang terpenting dan kunci terwujudnya tujuan karena tanpa disiplin yang baik sulit terwujud tujuan yang maksimal. Kedisiplan adalah kemampuan dan kesadaran untuk mentaati peraturan-peraturan perusahaan dan normanorma sosial.

\section{Pemberhentian ( separation)}

Adalah putusnya hubungan kerja seseorang dari suatu perusahaan. Disebabkan oleh keinginan karyawan, keinginan perusahaan, kontrak kerja berakhir, pensiun, dan sebab-sebab lainnya. Pelepasan ini diatur oleh UU No. 12 Tahun 1964. 


\section{PENUTUP}

Manajemen personalia adalah suatu ilmu dan seni untuk melaksanakan antara lain planning, organizing dan kontroling sehingga efektivitas dan efisiensi personalia dapat ditingkat kan semakasimal mungkin. Memang hrus kita ketahui bahwa sukses tidaknya suatu perusahaan /instansi tidak hanya tergantung dari kegiatan dalam bidang personalia , meskipun demikian peranan manajemen personalia cukup besar andilnya terhadap sukses tidaknya.

Manajemen personalia telah dilaksanakan sejak dulu oleh nenek moyang kita, hal ini ternyata dengan adanya bangunan seperti Borobudur, Piramid di Mesir dan sebagainya. Meskipun demikian karena situasi dan kondisi berubah serta kebutuhan yang mendesak, maka sejak abad ke-20 manajemen personalia mulai dekembangkan dan diusahakan untuk diterapkan.

MSDM adalah suatu bidang manajemen yang mempelajari hubungan dan peranan manusia dalam organisasi perusahaan. Jadi fokus yang dipelajari MSDM hanya masalah yang berkaitan dengan tenaga kerja manusia saja. MSDM lebih memfokuskan pembahasannya tentang pengaturan peranan manusia dalam mewujudkan tujuan yang optimal yang meliputi masalah perencanaan (human recources planning), pengorganisasian, pengarahan, pengendalian, pengadaan, pengembangan, kompensasi, pengintegrasian, pemeliharaan, kedisiplinan, dan pemberhentian tenaga kerja. 


\section{DAFTAR PUSTAKA}

B. Siswanto S. 2002. Manajemen Tenaga Kerja Indonesia. Pendekatan Administratif dan Operasional. Bandung; Bina Aksara.

Dessler, Gary (2000): Human Resource Management, International Edition, 8th Ed. Prentice Hall, Inc., Upper Saddle River, New Jersey.

Drucker, Peter (1988). The Coming of the New Organization. Harvard Business Review.

Fullerton, Jr., H. (1993). Another Look at the Labor Force. Monthly Labor review.

Handoko, T. Hani. 1998. Manajemen Personalia Dan Sumber Daya manusia. Yogyakarta: BPFE-Yogyakarta.

Hasibuan, S. P. Malayu. 2005. Manajemen Sumber Daya Manusia. Jakarta: PT. Bumi Aksara.

Kanter, Rosabeth Moss (1989). The New Managerial Works. Harvard Business Review, Mangkunegara, Anwar Prabu. 2002. Manajemen Sumber Daya Manusia Perusahaan. Bandung: PT. Remaja Rosdakarya

Siagian, Sondang P. 1998. Manajemen Sumber Daya Manusia. Jakarta: Bumi Aksara.

Veithzal, Rivai. 2005. Manajemen Sumber Daya Manusia Dari Teori Ke Praktek. Jakarta: PT. Raja Grafindo Persada. 